Terbit online pada laman web jurnal : http://ojs.unitas-pdg..ac.id/

Jurnal Manajemen dan Kewirausahaan

\begin{tabular}{l|l|l|} 
ISSN (Print) 2086-5031 ISSN (Online) 2615-3300 | DOI 10.31317 \\
\hline
\end{tabular}

\title{
Pengaruh Semangat Kerja dan Karakteristik Pekerjaan terhadap Kepuasan Kerja Karyawan di PT. Bank Mandiri (Persero), Tbk Cabang Bagindo Aziz Chan Padang
}

\author{
Nisa Ijriani, Henny Sjafitri, Nurlina \\ Fakultas Ekonomi, Universitas Tamansiswa Padang, Jl. Tamansiswa No. 9 Padang
}

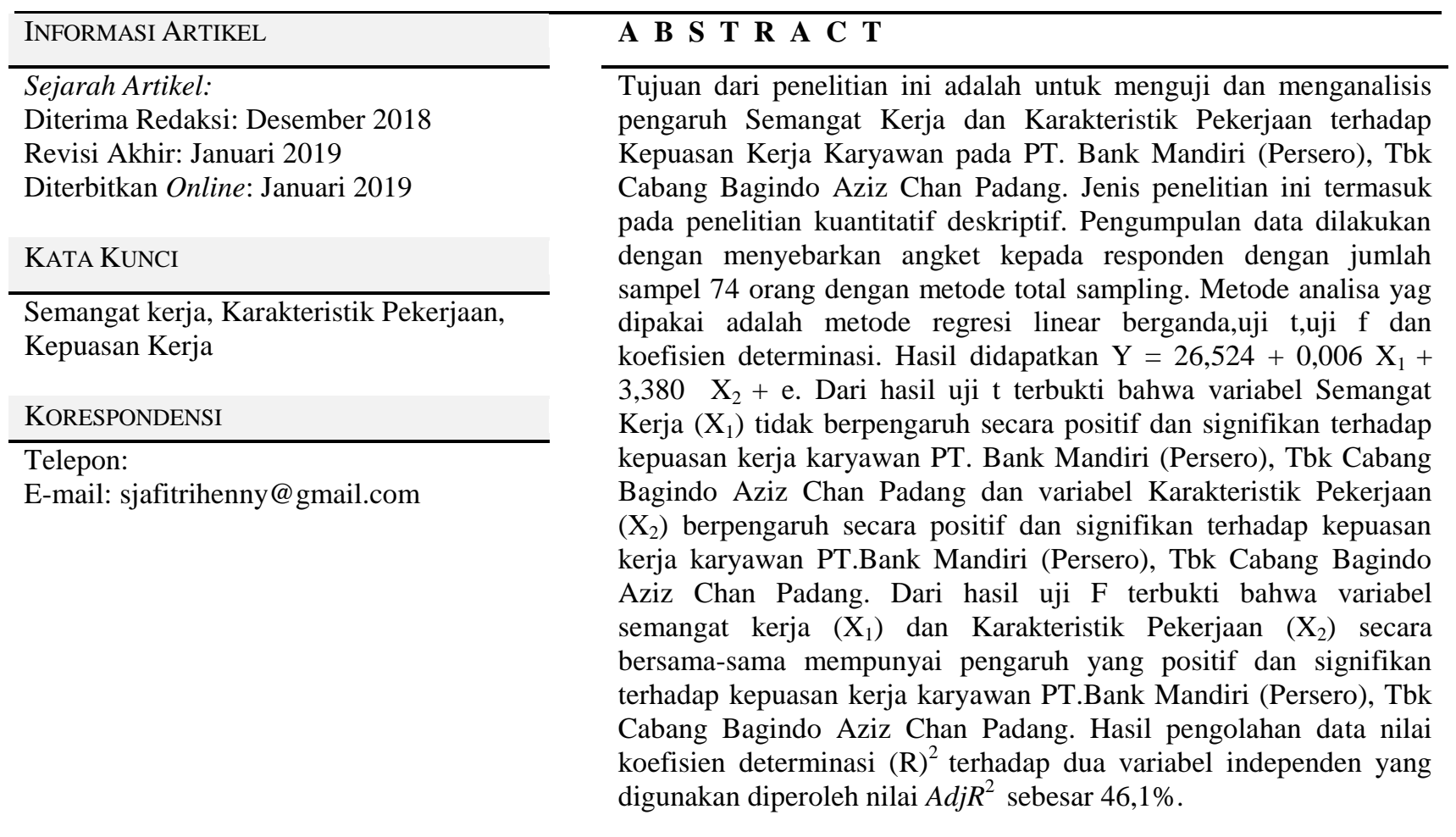

\section{PENDAHULUAN}

Manajemen Sumber Daya Manusia

semua bidang pekerjaan dan tingkat apapun (MSDM) pada hakikatnya merupakan aset utama dan bagian integral dari suatu organisasi maupun perusahaan. MSDM yang strategis memandang bahwa karyawan pada adalah baik secara struktural maupun fungsional.

Karyawan merupakan salah satu faktor produksi, oleh karena itu harus 
dimanfaatkan secara maksimal dan produktif.

Tujuan suatu perusahaan tidak akan dapat terwujud tanpa peran aktif karyawan meskipun alat-alat yang dimiliki perusahaan begitu canggih dan lengkap.

Pada umumnya, Semangat kerja karyawan di PT.Bank Mandiri (Persero), Tbk Cabang Bagindo Aziz Chan Padang yang tinggi, mereka dapat menyelesaikan pekerjaannya dengan baik, cepat dan akurat. Jika semangat kerja karyawan PT.Bank Mandiri (Persero), Tbk Cabang Bagindo Aziz Chan Padang. Apabila menurun akan mengakibatkan kualitas kerja tidak baik dan akan mengakibatkan kerugian pada perusahaan tersebut.

Terlihatnya kepuasan kerja karyawan pada disiplin kerja, dimana berdasarkan pengamatan yang peneliti lakukan terlihat banyaknya pegawai yang tidak disiplin seperti datang terlambat kekantor, pulang mendahului jam yang sudah ditentukan, sering tidak hadir tanpa alasan, sering meninggalkan kantor pada jam kerja dengan alasan pribadi dan lain-lain. Berdasarkan uraian latar belakang tersebut diatas, maka dapat diajukan sebuah penelitian dengan judul

"Pengaruh Semangat Kerja dan Karakteristik Pekerjaan terhadap Kepuasan Kerja Karyawan di PT. Bank Mandiri (Persero), tbk Cabang Bagindo Aziz Chan Padang".

\section{Perumusan Masalah}

Berdasarkan atas apa yang telah diuraikan pada latar belakang dan permasalahan diatas, maka dapat disimpulkan masalah sebagai berikut :

1. Apakah semangat kerja berpengaruh signifikan terhadap kepuasan kerja karyawan PT. Bank Mandiri (Persero), Tbk Cabang Bagindo Aziz Chan Padang?

2. Apakah karakteristik pekerjaan berpengaruh signifikan terhadap kepuasan kerja karyawan PT. Bank Mandiri (Persero),Tbk Cabang Bagindo Aziz Chan Padang?

3. Apakah semangat kerja dan karakteristik pekerjaan berpengaruh signifikan secara simultan terhadap kepuasan kerja karyawan PT. Bank Mandiri (Persero), Tbk Cabang Bagindo Aziz Chan Padang?

\section{Tujuan Penelitian}

Adapun tujuan penelitian yang penulis harapkan dari penelitian ini adalah:

1. Untuk mengetahui dan menganalisis pengaruh semangat kerja terhadap kepuasan kerja karyawan PT. Bank Mandiri (Persero),Tbk Cabang Bagindo Aziz ChanPadang.

2. Untuk mengetahui dan menganalisis pengaruh karakteristik pekerjaan terhadap kepuasan kerja karyawan PT. Bank Mandiri 
(Persero),Tbk Cabang Bagindo Aziz ChanPadang.

3. Untuk mengetahui dan menganalisis pengaruh semangat kerja dan karakteristik pekerjaan terhadap kepuasan kerja karyawan PT. Bank Mandiri (Persero),Tbk Cabang Bagindo Aziz ChanPadang.

\section{LANDASAN TEORI}

\section{Semangat Kerja}

Pengertian semangat kerja menurut Nitisemito (2010: 160) adalah "sebagai sesuatu yang positif dan sesuatu yang baik, sehingga mampu memberikan sumbangan terhadap pekerjaan dalam arti lebih baik".

Menurut Purwanto (2012:82), menyatakan bahwa semangat kerja adalah reaksi emosional dan mental dari seseorang terhadap pekerjaannya. Semangat kerja mempengaruhi kualitas dan kuantitas pekerjaan seseorang. Menurut Hasibuan 2014 Semangat kerja adalah keinginan dan kesungguhan seseorang mengerjakan pekerjaannya dengan baik serta berdisiplinan untuk mencapai prestasi kerja yang maksimal. Triadityo, 2012 mengatakan bahwa semangat kerja adalah kondisi seseorang yang menunjang dirinya

Sesuai dengan penjabaran di atas, penulis menyimpulkan dengan meningkatkannya semangat kerja, maka pekerjaan akan lebih cepat diselesaikan dan semua pengaruh buruk dari menurunya semangat kerja seperti absensi dan gairah kerja yang berarti diharapkan juga meningkatkan produktivitas karyawan. Semangat kerja dapat diartikan pernyataan ringkas yang beraneka ragam yang menekankan sehubungan dengan pekerjaan mereka.

\section{Faktor-Faktor Semangat Kerja}

Faktor-faktor yang mempengaruhi turunnya atau melemahnya semangat kerja menurut Nitisemito (2010: 167), yaitu:

1. Upah yang rendah

Upah yang terlalu rendah akan mengakibatkan karyawan lesu di dalam bekerja, karena kebutuhan atau hidupnya tidak terpengaruh dari pekerjaan yang ia kerjakan sehingga semangat kerja akan menurun

2. Lingkungan kerja yang buruk

Lingkungan kerja yang buruk akan mengganggu konsentrasi karyawan dalam bekerja, sehingga apa yang mereka kerjakan tidak sesuai yang diharapkan perusahaan.

3. Kurangnya disiplin

Kurangnya kedisiplinan akan mempengaruhi terhadap penyelesaian kerja, sehingga karyawan dituntut untuk menyelesaikan pekerjaan dengan tepat waktu.

4. Gaya kepemimpinan yang buruk 
Gaya kepemimpinan yang buruk akan mempengaruhi semangat kerja karyawan dalam bekerja, karena apabila pemimpin terlalu otoriter dan hanya mementingkan kepentingan perusahaan tanpa memperdulikan karyawan, maka semangat kerja karyawan akan menurun

5. Kurang informasi

Kurangnya informasi yang diberikan kepada karyawan akan mengakibatkan lambatnya penyelesaian pekerjaan yang dilakukan oleh karyawan, karena informasi yang dibutuhkan karyawan sangat kurang.

\section{Indikator Semangat Kerja}

Indikator semangat kerja yang dikemukakan oleh Nitisemito (2010: 427), yang diantaranya adalah sebagai berikut:

1. Naiknya produktivitas karyawan

Karyawan yang semangat kerjanya tinggi cenderung melaksanakan tugas-tugas sesuai waktu, tidak menunda pekerjaan dengan sengaja, serta mempercepat pekerjaan dan sebagainya. Oleh karena itu harus dibuat standar kerja untuk mengetahui apakah produktivitas karyawan yang tinggi apa tidak.

2. Tingkat absensi rendah

Tingkat absensi rendah merupakan salah satu indikasi meningkatnya semangat kerja,karena persentase absen seluruhkaryawan rendah.

3. Labour turn over
Tingkat karyawan keluar masuk, karyawan yang menurun merupakan salah satu indikasi meningkatnya semangat kerja.Hal ini dapat disebabkan oleh kesenangan mereka bekerja pada perusahaan tersebut. Tingkat keluar masuk karyawan yang tinggi dapay menggangu jalannya perusahaan.

\section{Karakteristik Pekerjaan}

Robbins \& Judge (2008) menyatakan bahwa karakteristik pekerjaan adalah suatu pendekatan terhadap pemerkayaan jabatan yang dispesifikasikan kedalam 5 dimensi karakteristik inti yaitu keragaman ketrampilan (skill variety), jati diri dari tugas (task identity), signifikasi tugas (task significance), otonomi (autonomy) dan umpan balik .

Pada saat seorang karyawan mengalami tekanan dalam pekerjaannya maka kepuasan kerjanya mungkin tidak mereka peroleh. Hal ini akan mengganggu atau mempengaruhi hasil kerja dari karyawan tersebut. Oleh karena itu para pimpinan perusahaan harus jeli melihat situasi seperti ini agar tekanan pekerjaan tidak menjadi halangan karyawannya bekerja dengan baik.

\section{Karakteristik Pekerjaan}

Menurut Munandar (dalam Moekijat, 2003) lima ciri-ciri intrinsik pekerjaan yang 
memperlihatkan kaitannya dengan kepuasan kerja untuk berbagai macam pekerjaan.

Kelima ciri intrinsik tersebut adalah sebagai berikut:

1. Skill Variety (Keragaman keterampilan atau variasi pekerjaan).

2. Task Identity (Jati diri tugas).

3. Task Significance.

4. Otonomi

5. Umpan balik

\section{Indikator Karakteristik Pekerjaan}

Karakteristik pekerjaan mengemukakan bahwa pekerjaan apapun bisa dideskripsikan dalam 5 dimensi pekerjaan utama, yaitu: (Robbins, 2003:219):

1. Keanekaragaman keterampilan (Skill variety)

Sejauh mana pekerjaan itu menuntut keragaman kegiatan yang berbeda sehingga pekerjaan itu dapat menggunakan sejumlah keterampilan dan bakat yang berbeda.

2. Identitas tugas (Task Identity)

Sejauh mana pekerjaan itu menuntut diselesaikan seluruh potongan kerja secara utuh dan dapat dikenali.

3. Arti tugas (Task Significance)

Sejauh mana pekerjaan itu mempunyai dampak yang cukup besar pada kehidupan atau pekerjaan orang lain.

4. Otonomi (Autonomy)
Sejauh mana pekerjaan itu memberikan kebebasan, ketidak tergantungan, dan keleluasaan yang cukup besar kepada individu dalam menjadwalkan pekerjaan itu dan dalam menentukan prosedur yang digunakan dalam menyelesaikan pekerjaan itu.

\section{Umpan balik (Feedback)}

Sejauh mana pelaksanaan kegiatan pekerjaan yang dituntut oleh pekerjaan itu menghasilkan diperolehnya informasi yang langsung dan jelas oleh individu mengenai keefektifan kinerjanya.

\section{Kepuasan Kerja}

Kepuasan kerja didefinisikan sebagai sikap umum individu terhadap pekerjaannya, dalam hal ini adalah karyawan.Karyawan dapat menilai seberapa puas atau tidak puas dirinya dengan pekerjaannya (Robbins, 2007).

\section{Faktor- faktor kepuasan kerja}

Faktor-faktor yang mempengaruhi kepuasan kerja, menurut Mangkunegara (2015:120) yaitu :

1. Faktor pegawai, yaitu kecerdasan (IQ), kecakapan khusus, umur, jenis kelamin, kondisi fisik, pendidikan, pengalaman kerja, masa kerja, kepribadian, emosi, cara berfikir, persepsi, dan sikap kerja.

2. Faktor pekerjaan, yaitu jenis pekerjaan, struktur organisasi, pangkat (golongan), kedudukan, mutu pengawasan, jaminan 
financial, kesempatan promosi jabatan, interaksi sosial, dan hubungan kerja.

\section{Indikator-indikator kepuasan kerja}

Robbins (2012:22) mengatakan bahwa faktor yang menentukan kepuasan kerja adalah :

1. Kerja yang secara mental menantang Pekerjaan yang kurang menantang menciptakan kebosanan, tetapi yang terlalu banyak menantang menciptakan frustasi dan perasaan gagal.Pada kondisi yang sedang, kebanyakan pegawai mengalami kesenangan dan kepuasan.

2. Imbalan yang pantas

Bila upah dilihat sebagai adil yang didasarkan pada tuntutan pekerjaan, tingkat keterampilan individu, dan standar pengupahan komunitas kemungkinan besar akan dihasilkan kepuasan.

3. Kondisi kerja yang mendukug

Pegawai peduli akan lingkungan kerja yang baik untuk kenyamanan pribadi maupun untuk memudahkan pegawai dalam mengerjakan tugas dengan baik.

4. Rekan kerja yang mendukung

Bagi kebanyakan pegawai, kerja juga mengisi kebutuhan akan interaksi sosial. Oleh karena itu, tidak mengejutkan bila mempunyai rekan sekerja yang ramah dan mendukung menghantar kepuasan kerja karyawan yang meningkat.

\section{Hipotesis Penelitian}

Berdasarkan kerangka konseptual yang dikemukakan diatas, model penelitian yang ditawarkan mengenai hubungan kepuasan kerja dan komitmen organisasi terhadap kinerja karyawan.

$\mathrm{H}_{1}=$ Diduga Semangat Kerja berpengaruh signifikan terhadap Kepuasan Kerja Karyawan PT.Bank Mandiri (Persero), Tbk Cabang Bagindo Aziz Chan Padang.

$\mathrm{H}_{2}=$ Diduga Karakteristik Pekerjaan berpengaruh signifikan terhadap Kepuasan Kerja Karyawan PT.Bank Mandiri (Persero), Tbk Cabang Bagindo Aziz Chan Padang.

$\mathrm{H}_{3}=$ Diduga Semangat Kerja dan Karakteristik Pekerjan secara simultan berpengaruh signifikan terhadap Kepuasan Kerja Karyawan PT.Bank Mandiri (Persero), Tbk Cabang Bagindo Aziz Chan Padang.

\section{METODOLOGI PENELITIAN}

\section{Populasi dan sampel Penelitian}

Dalam penelitian ini yang menjadi populasinya yaitu karyawan PT. Bank Mandiri (Persero) Tbk, cabang Bagindo Aziz Chan Padang tahun 2018 sebanyak 74 orang. Dan teknik pengambilan sampel dalam penelitian ini menggunakan total sampling, semua pegawai dijadikan sampel pada karyawan PT. Bank Mandiri (Persero) Tbk, 
cabang Bagindo Aziz Chan Padang sebanyak

74 orang dengan alasan jika populasi kurang dari 100 maka diambil 10-15\% atau 20-25\% tergantung dari kemampuan dalam penelitian ini menggunakan teknik total sampling karena jumlah populasi yang kecil.

\section{Jenis Data dan Sumber Data}

Data yang digunakan dalam penelitian ini adalah :

1. Data kuantitatif dalam penelitian ini adalah data jumlah karyawan karyawan PT. Bank Mandiri (Persero) Tbk, cabang Bagindo Aziz Chan Padang.

2. Data kualitatif dalam penelitian ini adalah lokasi penelitian dan gambaran umum perusahaan.

3. Data Primer, berupa angket penelitian yang disebarkan kepada responden.

4. Data Sekunder, berupa jurnal, literaturliteratur yang berkaitan dalam penelitian ini.

\section{Teknik Pengumpulan Data}

Dalam penelitian ini penulis menggunakan teknik pengumpulan data sebagai berikut:

\section{Observasi}

2. Angket

3. Kepustakaan

\section{Teknik Analisis Data}

1. Uji Validitas

2. Uji Reliabilitas

3. Analisa Regresi Linear Berganda

4. Uji t (Parsial)

5. Uji F (Simultan)

6. $\mathrm{Uji}^{2}$ (Koeffisien Determinasi)

\section{HASIL PENELITIAN}

\section{Analisis Linear Berganda}

Menurut Sugiyono, (2012:192) regresi linear berganda digunakan untuk mencari besarnya koefisien pengaruh (positif atau negatif) antara variabel bebas semangat kerja $\left(\mathrm{X}_{1}\right)$ dan variabel bebas karakteristik pekerjaan $\left(\mathrm{X}_{2}\right)$ terhadap variable tidak bebas kepuasan kerja (Y). Berdasarkan uji regresi berganda yang dilakukan dapat dilihat pada tabel 4.1.2. di bawah ini:

Tabel 1. Hasil Uji Regresi Linear Berganda

\begin{tabular}{|c|c|c|c|c|c|c|c|c|c|c|c|c|c|}
\hline \multicolumn{14}{|c|}{ Coefficients $^{\mathrm{a}}$} \\
\hline \multirow{2}{*}{\multicolumn{2}{|c|}{ Model }} & \multicolumn{2}{|c|}{$\begin{array}{c}\text { Unstandardized } \\
\text { Coefficients }\end{array}$} & \multirow{2}{*}{$\begin{array}{c}\text { Standardized } \\
\text { Coefficients } \\
\text { Beta }\end{array}$} & \multirow[t]{2}{*}{$\mathrm{t}$} & \multirow[t]{2}{*}{ Sig. } & \multicolumn{2}{|c|}{$\begin{array}{c}95.0 \% \text { Confidence } \\
\text { Interval for B }\end{array}$} & \multicolumn{3}{|c|}{ Correlations } & \multicolumn{2}{|c|}{$\begin{array}{c}\text { Collinearity } \\
\text { Statistics }\end{array}$} \\
\hline & & B & $\begin{array}{l}\text { Std. } \\
\text { Error }\end{array}$ & & & & $\begin{array}{l}\text { Lower } \\
\text { Bound }\end{array}$ & $\begin{array}{l}\text { Upper } \\
\text { Bound }\end{array}$ & $\begin{array}{l}\text { Zero- } \\
\text { order }\end{array}$ & Partial & Part & $\begin{array}{c}\text { Tolera } \\
\text { nce }\end{array}$ & VIF \\
\hline \multirow{3}{*}{1} & (Constant) & 26.524 & 3.421 & & 7.754 & .000 & 19.703 & 33.345 & & & & & \\
\hline & $\begin{array}{l}\text { Semangat } \\
\text { Kerja }\end{array}$ & .006 & .139 & .004 & .043 & .966 & -.271 & .283 & .024 & .005 & .004 & .999 & 1.001 \\
\hline & $\begin{array}{l}\text { Karakteristik } \\
\text { Pekerjaan }\end{array}$ & 3.380 & .421 & .690 & 8.029 & .000 & $2.54 \mathrm{t}$ & asil & $\$ 90$ & .690 & .690 & .999 & 1.001 \\
\hline
\end{tabular}


Uji $\mathrm{t}$ pada dasarnya menunjukkan seberapa jauh pengaruh satu variabel penjelas atau bebas secara individual dalam menerangkan variasi variabel terikat, Ghozali (2005). Pengujian ini bertujuan untuk menguji pengaruh variabel bebas (Semangat kerja dan Karakteristik pekerjaan) terhadap variabel terikat (Kepuasan kerja) secara terpisah atau parsial. Berdasarkan uji $\mathrm{t}$ yang dilakukan dapat dilihat pada tabel 4.13.dibawah ini:
Berdasarkan uji $F$ yang dilakukan dapat dilihat pada tabel 4.14 dibawah ini:

Tabel 3. Hasil Uji F berdasarkan Analisis Regresi Berganda

\begin{tabular}{|c|c|c|c|c|c|c|}
\hline \multicolumn{7}{|c|}{$\mathrm{ANOVA}^{\mathrm{a}}$} \\
\hline \multicolumn{2}{|c|}{ Model } & $\begin{array}{l}\text { Sum of } \\
\text { Squares }\end{array}$ & Df & Mean Square & F & Sig. \\
\hline \multirow{3}{*}{1} & Regression & 864.397 & 2 & 432.199 & 32.268 & $.000^{b}$ \\
\hline & Residual & 950.967 & 71 & 13.394 & & \\
\hline & Total & 1815.365 & 73 & & & \\
\hline
\end{tabular}

a. Dependent Variable: Kepuasan Kerja

b. Predictors: (Constant), Karakteristik Pekerjaan, Semangat Kerja

Sumber : Data yang diolah menggunakan IBM SPSS Statistic 2.0

\section{Koefisien Determinasi $\left(\mathbf{R}^{2}\right)$}

Tabel 2. Hasil Uji t (Parsial)

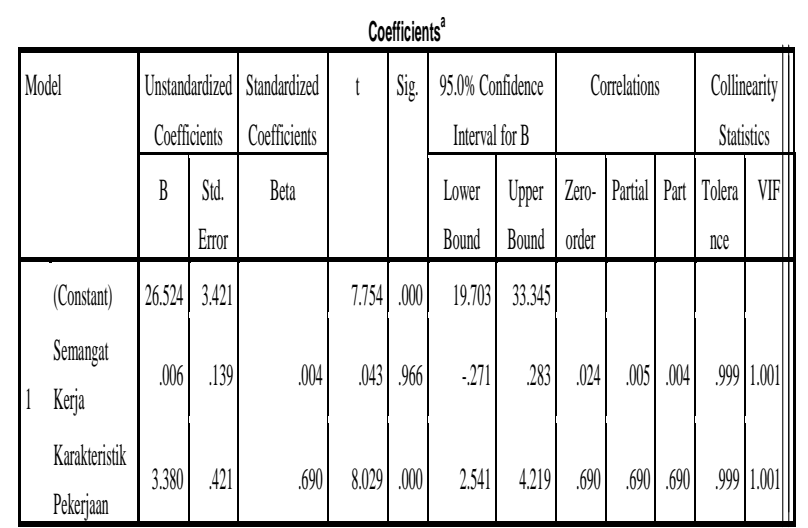

Sumber :Data primer yang diolah, 2018

\section{Uji F (Simultan)}

Dalam penelitian ini pengujian hipotesis secara simultan dimaksudkan untuk mengukur besarnya pengaruh variabel bebas (Semangat kerja dan Karakteristik pekerjaan) terhadap variabel terikatnya (Kepuasan kerja).
Arikunto (2013:334) Koefisien determinasi $\left(\mathrm{R}^{2}\right)$ dimana $\mathrm{R}^{2}$ selalu dalam Presentase, digunakan untuk mengetahui variasi yang bisa dijelaskan antara variabel $\mathrm{X}$ terhadap variabel $\mathrm{Y}$. Berdasarkan uji $\mathrm{R}^{2}$ yang dilakukan dapat dilihat pada tabel 4.15 dibawah ini:

\section{Tabel 4. Model Summary}

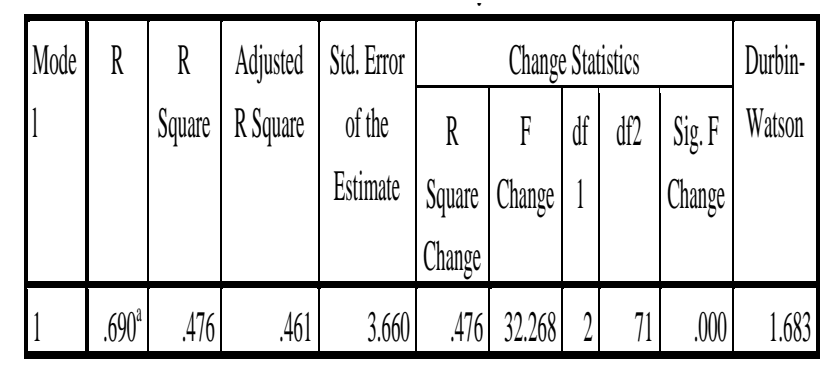

a. Predictors: (Constant), Karakterisitik Pekerjaan, Semangat Kerja

b. Dependent Variable: Kepuasan Kejja

Sumber :Data yang diolah menggunakan IBM SPSS Statistic 2.0

\section{KESIMPULAN}


Berdasarkan analisa dan evaluasi permasalahan yang dilakukan penulis dalam penulisan skripsi ini, maka dapat disimpulkan bahwa:

1. Semangat kerja $\left(X_{1}\right)$ tidak berpengaruh secara positif dan signifikan terhadap kepuasan kerja karyawan PT. Bank Mandiri (Persero) Tbk cabang Bagindo Aziz Chan Padang, yaitu nilai $t_{\text {hitung }}<\mathrm{t}_{\text {tabel }}$ $(0,043<1,666)$ maka $\mathrm{H}_{0}$ diterima $\mathrm{H}_{1}$ ditolak dengan nilai signifikan $0,966>0,005$. Dengan demikian secara parsial variabel independen yaitu semangat kerja tidak berpengaruh secara positif dan signifikan terhadap variabel dependen yaitu kepuasan kerja karyawan PT. Bank Mandiri (Persero) Tbk cabang Bagindo Aziz Chan Padang.

2. Terdapat pengaruh positif dan signifikan variabel karakteristik pekerjaan $\left(\mathrm{X}_{2}\right)$ terhadap kepuasan kerja karyawan PT. Bank Mandiri (Persero) Tbk cabang Bagindo Aziz Chan Padang, yaitu nilai $t_{\text {hitung }}>\mathrm{t}_{\text {tabel }}(8,029>1,666)$ maka $\mathrm{H}_{0}$ ditolak $\mathrm{H}_{2}$ diterima dengan nilai signifikan $0,000<$ 0,005. Dengan demikian secara parsial variabel independen yaitu karakteristik pekerjaan berpengaruh signifikan terhadap variabel dependen yaitu kepuasan kerja karyawan PT. Bank Mandiri (Persero) Tbk, cabang Bagindo Aziz Chan Padang.

3. Secara bersamaan bahwa ada pengaruh yang positif dan secara simultan signifikan antara semangat kerja $\left(\mathrm{X}_{1}\right)$ dan karakteristik pekerjaan $\left(\mathrm{X}_{2}\right)$ terhadap kepuasan kerja karyawan PT. Bank Mandiri (Persero) Tbk cabang Bagindo Aziz Chan Padang, hal ini dapat di buktikan dengan $\mathrm{F}$ hitung $>\mathrm{F}$ tabel atau 32,268>3.13 dan tingkat signifikan 0,000 $<0,005$ maka Ho ditolak dan $\mathrm{H}_{3}$ diterima sehingga dapat disimpulkan bahwa variabel semangat kerja $\left(\mathrm{X}_{1}\right)$ dan karakteristik pekerjaan $\left(\mathrm{X}_{2}\right)$ secara bersamaan berpengaruh signifikan terhadap kepuasan kerja karyawan PT. Bank Mandiri (Persero) Tbk, cabang Bagindo Aziz Chan Padang.

\section{DAFTAR PUSTAKA}

Alex, S. Nitisemito. 2010, Manajemen Personalia Manajemen Sumber Daya Manusia. Edisi ketiga, Jakarta: Ghalia Indonesia.

Aritonang. 2007. Uji Validitas dan Reliabilitas: Pustaka Pelajar.

Arikunto, Suharsimi. 2013. Dasar-dasar Evaluasi Pendidikan, Jakarta: Bumi Aksara.

Chandra, dkk. 2014. Pengaruh Kepuasan Kerja dan Kinerja Karyawan Hotel 'D' Season, Surabaya.

Darmawan, D. 2009. Variabel Semangat Kerja dan Indikator Pengukurannya, Jakarta: kencana.

Donni, Junni Priansa. 2014. Perencanaan dan Pengembangan Sumber daya Manusia. Penerbit Bandung: Alfabeta.

Gitosudarmo, Indriyo. 2000. Perilaku Keorganisasian. Edisi Pertama. Cetakan Kedua. Penerbit BPFE. Yogyakarta. 
Ghozali, Imam. 2005. Aplikasi Analisis Multivariate dengan Program SPSS Edisi 3. Bandung: Alfabeta

Hasibuan, Malayu. 2008. Manajemen Sumber Daya Manusia. Jakarta: PT Bumi Aksara.

Husein, Umar. 2008. Metode Penelitian untuk Skripsi dan Tesis Bisnis. Jakarta, Penerbit Erlangga.

Indrianto, Nur dan Supomo. 2002. Metodologi Penelitian Bisnis untuk Akuntansi dan Manajemen, Edisi Pertama, Yogyakarta: BPFE.

Johnson, B and Christensen, L. 2012. Educational Research: Quantitative, Qualitative, and Mixed Approaches. London: SAGE Publications,Inc.

J. Supranto. 2001. Statistik Teori dan Aplikasi. Edisi: 6, Jakarta: Erlangga.

Moekijat. 2009. Manajemen Personalia dan Sumber Daya, Mandesia Maju, Jakarta.

Moekijat. 2003. Manajemen Tenaga Kerja dan Hubungan Kerja. Bandung: CV Pionir Jaya.

Mathis, R.L. dan J.H Jackson. 2006, Human Resaurce Management: Manajemen
Sumber Daya Manusia. Terjemahan Dian Angelia. Salemba Empat. Jakarta

Musfiqon, 2012. Metode Penelitian Kualitatif Kuantitatif dan R\&D. Bandung; Alfabeta.

Ngambi, H.C. 2011. The Relationship Between Leadership and Employe Morale In Higher Education, Vol. 5(3), PP 762-776.

Pasolong, Harbani. 2007. Teori Administrasi Publik, Bandung. Alfabeta

Robbins dan Judge, 2008. Perilaku Organisasi, Edisi Duabelas, Penerbit Salemba Empat. Jakarta

Robbins, Stephen P. 2002. Prinsip-prinsip Perilaku Organisasi. Edisi Kelima Erlangga, Jakarta.

Robbins, Stephen P. 2007. Perilaku Organisasi, Edisi: 12, Jakarta: Salemba Empat.

Simamora. 2006. Karakteristik Pekerjaan dan Organisasi.

Sugiyono. 2012. Metode Penelitian Bisnis. Bandung: Alfabeta. 